\title{
Effect of Dopant Compensation on the Behavior of Dissolved Iron and Iron-Boron Related Complexes in Silicon
}

\author{
Xiaodong Zhu, ${ }^{1}$ Xuegong Yu, ${ }^{1}$ Peng Chen, ${ }^{1}$ Yong Liu, ${ }^{1}$ \\ Jan Vanhellemont, ${ }^{1,2}$ and Deren Yang ${ }^{1}$ \\ ${ }^{1}$ State Key Laboratory of Silicon Materials and Department of Materials Science and Engineering, Zhejiang University, \\ Hangzhou 310027, China \\ ${ }^{2}$ Department of Solid State Sciences, Ghent University, Krijgslaan 281 S1, 9000 Ghent, Belgium
}

Correspondence should be addressed to Xuegong Yu; yuxuegong@zju.edu.cn

Received 24 April 2015; Accepted 28 June 2015

Academic Editor: Yanfa Yan

Copyright (C) 2015 Xiaodong Zhu et al. This is an open access article distributed under the Creative Commons Attribution License, which permits unrestricted use, distribution, and reproduction in any medium, provided the original work is properly cited.

\begin{abstract}
The behavior of iron, iron-boron (FeB) pairs, and iron-boron-phosphorus (FeB-P) complexes has been studied in B-doped Czochralski silicon with phosphorus $(\mathrm{P})$ compensation and compared with that in uncompensated material. The interstitial iron concentration has been measured at temperatures from 50 to $270^{\circ} \mathrm{C}$. The apparent binding energy $\left(E_{b}\right)$ of FeB in compensated silicon is $(0.25 \pm 0.03) \mathrm{eV}$, significantly lower than the $(0.53 \pm 0.02) \mathrm{eV}$ in uncompensated silicon. Possible reasons for this reduction in binding energy are discussed by experimental and calculation methods. The results are important for understanding and controlling the behavior of Fe in compensated silicon.
\end{abstract}

Low-cost silicon feedstock for photovoltaic (PV) industry contains dopant species and metal impurities, in most cases boron $(\mathrm{B})$, phosphorous $(\mathrm{P})$, and iron $(\mathrm{Fe})$ [1-3]. In some cases, a significant dopant compensation also exists, which affects the properties of the silicon substrate and reduces the efficiency of the solar cells $[4,5]$. One of the unresolved issues of compensated B-doped silicon is the influence of compensation on the behavior and properties of dissolved iron and of iron-boron pairs (FeB). The stable configuration of $\mathrm{FeB}$ is that an interstitial $\mathrm{Fe}$ atom $\left(\mathrm{Fe}_{\mathrm{i}}\right)$ occupies a tetrahedral $(T)$ interstitial site close to a substitutional B atom $\left(B_{s}\right)$ whereby the positively charged $\mathrm{Fe}$ atom is attracted by the negatively charged B atom $[6,7]$. In any B-doped p-type silicon wafer, even when it is strongly compensated, $\mathrm{Fe}_{\mathrm{i}}$ is always positively charged and will therefore form pairs with the negatively charged acceptor atoms [8]. As the B atoms are quasi immobile in the relevant temperature range and the pairing reaction itself is very fast, the formation kinetics of $\mathrm{FeB}$ are determined only by $\mathrm{Fe}_{\mathrm{i}}^{+}$diffusion $[9,10]$ which is little or not affected by the presence of compensating dopants [8]. The migration energy of $\mathrm{Fe}_{i}{ }^{+}$, which is close to the formation energy of $\mathrm{FeB}$, has been reported to be in the range of 0.58 to $0.81 \mathrm{eV}$ [7]. For compensated silicon, Istratov et al. [7] reported that the effect of $\mathrm{P}$ on $\mathrm{Fe}_{\mathrm{i}}{ }^{+}$migration energy can be ignored. The equilibrium concentration of $\mathrm{Fe}_{i}{ }^{+}$ $\left(N\left(\mathrm{Fe}_{\mathrm{i}}^{+}\right)\right)$depends on the binding energy $\left(E_{b}\right)$ of $\mathrm{FeB}$, the temperature, and the $\mathrm{B}$ concentration [11], whereby $N\left(\mathrm{Fe}_{i}{ }^{+}\right)$ can be monitored by the variation of carrier lifetime before and after the association of $\mathrm{FeB}$ [11]. $E_{b}$ is in the range of 0.45 to $0.65 \mathrm{eV}$ as reported in a previous study [7, 12]. For compensated silicon, first-principles calculations show that there is a binding energy of $0.82 \mathrm{eV}$ when $B_{s}$ pairs with substitutional $\mathrm{P}\left(\mathrm{P}_{\mathrm{s}}\right)$ located at its second-neighbor sites [13]. This pairing of $\mathrm{B}$ and $\mathrm{P}$, which can occur during crystallization from a melt, will also lead to a different binding energy of Fe with the B-P pair due to the fact that also the apparent thermodynamic properties of $\mathrm{FeB}$ (in fact of the carrier recombination centers associated with the FeB-P and FeB complexes), as determined from lifetime measurements, will be different in compensated material. Comparing the Fe behavior in compensated silicon with that in uncompensated silicon will therefore yield information on $E_{b}$ of iron-boron-phosphorus (FeB-P) related complexes in compensated material. 
At temperatures below $100^{\circ} \mathrm{C}$, the formation of $\mathrm{FeB}$ is the dominant process in uncompensated material, while a recovery of $\mathrm{Fe}_{\mathrm{i}}$ species and a reduction in the concentration of $\mathrm{FeB}$ are observed at temperatures between 100 and $200^{\circ} \mathrm{C}$ [7]. At temperatures above $200^{\circ} \mathrm{C}$, acceptors can no longer provide stable traps for iron and iron will diffuse towards more stable sinks such as dislocations, precipitates, or even the sample surface [7, 14]. Zeng et al. [14] reported that iron forms small precipitates from 300 to $700^{\circ} \mathrm{C}$ in as-received Czochralski (CZ) silicon and that Fe precipitation is a diffusion-limited process that follows closely Ham's law [15]. Krain et al. [16] reported that the precipitation activation energy is close to the $\mathrm{Fe}_{\mathrm{i}}$ migration energy. To limit the influence of $\mathrm{Fe}$ precipitation, $E_{b}$ is determined at temperatures below $200^{\circ} \mathrm{C}$ in our experiment. To completely dissociate FeB for B concentrations above $10^{16} \mathrm{~cm}^{-3}$, however, the temperature must be higher than $300^{\circ} \mathrm{C}$ in uncompensated Si [17]. The total iron concentration can be determined before and after the light induced dissociation of $\mathrm{FeB}$ (or Fe-B related complexes) both in compensated and in uncompensated silicon [8].

In this letter, the effect of dopant compensation in silicon on the behavior and properties of $\mathrm{Fe}$ is investigated at temperatures between 50 and $270^{\circ} \mathrm{C}$. The concentration of single positively charged interstitial iron atoms $N\left(\mathrm{Fe}_{\mathrm{i}}{ }^{+}\right)$in $\mathrm{B}$ and $\mathrm{P}$ codoped silicon has been compared with that in uncompensated silicon in this temperature range.

$1 \times 1 \mathrm{~cm}^{2}$ p-type $\langle 100\rangle$ crystalline silicon samples are prepared. One set of samples (labeled CZ-1) is only B-doped, with a $\mathrm{B}$ concentration $\left(N_{\mathrm{B}}\right)$ of $1.1 \times 10^{16} \mathrm{~cm}^{-3}$. The second set of samples (labeled CZ-2) is $\mathrm{B}$ and $\mathrm{P}$ codoped, with $N_{\mathrm{B}}$ of $4.10 \pm 0.04 \times 10^{16} \mathrm{~cm}^{-3}$ and $\mathrm{P}$ concentration $\left(N_{\mathrm{P}}\right)$ of $1.20 \pm 0.01 \times 10^{16} \mathrm{~cm}^{-3}$, as determined by secondary ion mass spectroscopy (SIMS). The interstitial oxygen concentration in all the samples is about $10^{18} \mathrm{~cm}^{-3}$, as determined by Fourier transform infrared spectroscopy (FTIR) using the $3.14 \times 10^{17} \mathrm{~cm}^{-2}$ calibration factor. After dipping in $0.1 \mathrm{~mol} / \mathrm{L}$ ferric nitric acid $\left(\mathrm{Fe}\left(\mathrm{NO}_{3}\right)_{3}\right)$ solution, $\mathrm{Fe}$ was diffused into the samples by annealing in an argon ambient at $800^{\circ} \mathrm{C}$ for $2 \mathrm{~h}$, followed by quenching in air. Fe concentration that can be introduced into the samples at that temperature is of the order of $10^{12} \mathrm{~cm}^{-3}$ according to the solubility of iron in silicon [7]. After that, the samples were subjected to chemical polishing and surface-passivation with $\mathrm{SiN}_{x}: \mathrm{H}$ films by plasma-enhanced chemical vapor deposition (PECVD) technique. Then, the samples were kept in the dark for more than $24 \mathrm{~h}$ to allow the dissolved iron atoms to diffuse and form complexes with dopant atoms until an equilibrium is established at room temperature. Subsequently, the samples were annealed at different temperatures in the range between 50 and $270^{\circ} \mathrm{C}$ until equilibrium was reached at each temperature, followed by cooling in water. The applied anneal times were at $50^{\circ} \mathrm{C} / 2 \mathrm{~h}$, at $100^{\circ} \mathrm{C} / 1 \mathrm{~h}$, at $120^{\circ} \mathrm{C} / 40 \mathrm{~min}$, at $140^{\circ} \mathrm{C} / 30 \mathrm{~min}$, at $160^{\circ} \mathrm{C} / 25 \mathrm{~min}$, at $180^{\circ} \mathrm{C} / 17 \mathrm{~min}$, and above $200^{\circ} \mathrm{C} / 10 \mathrm{~min}$. After $200^{\circ} \mathrm{C} / 10 \mathrm{~min}$ anneal, the annealing times $\left(<200^{\circ} \mathrm{C}\right)$ were determined when the carrier lifetimes reached the equilibrium state at each temperature. Note that the effects of the B-O complexes were eliminated after $200^{\circ} \mathrm{C} / 10 \mathrm{~min}$ anneal, since the $\mathrm{B}-\mathrm{O}$ complexes were dissociated. The evolution of carrier lifetime with the anneal temperature is measured by the microwave-detected photoconductance decay (MWPCD) technique using Semilab WT2000 instrument. In all experiments the change of the carrier density after FeB dissociation is less than $6 \%$.

It is well known that association and dissociation of FeB in silicon are reversible, which can be expressed by [9]:

$$
\mathrm{Fe}_{\mathrm{i}}^{+}+\mathrm{B}_{\mathrm{s}} \rightleftharpoons \mathrm{Fe}_{\mathrm{i}} \mathrm{B}_{\mathrm{s}}
$$

Similarly, the formation of FeB-P complexes maybe expressed by

$$
\mathrm{Fe}_{\mathrm{i}}^{+}+\left(\mathrm{B}_{\mathrm{s}}^{-}-\mathrm{P}_{\mathrm{s}}^{+}\right) \rightleftharpoons \mathrm{Fe}_{\mathrm{i}} \mathrm{B}_{\mathrm{s}}-\mathrm{P}_{\mathrm{s}}
$$

where the positively charged $\mathrm{P}$ atom is assumed to be located close to the negatively charged B atom. Since $\mathrm{Fe}_{\mathrm{i}}{ }^{+}$ and $\mathrm{FeB}$ have different recombination properties [7], $\mathrm{Fe}_{\mathrm{i}}{ }^{+}$ concentration can be determined by lifetime measurements on uncompensated samples, using the following equation [18]:

$$
N\left(\mathrm{Fe}_{\mathrm{i}}\right)=C\left(\frac{1}{\tau_{0}}-\frac{1}{\tau_{T}}\right),
$$

where the prefactor $C$ is $3.4 \times 10^{13} \mu \mathrm{s} \cdot \mathrm{cm}^{-3}$ for the WT2000 instruments as determined from the recombination parameters of $\mathrm{Fe}_{\mathrm{i}}^{+}$and $\mathrm{FeB}, \tau_{0}$ is the carrier lifetime when all the $\mathrm{Fe}_{\mathrm{i}}$ atoms have paired with $\mathrm{B}$, and $\tau_{T}$ is the carrier lifetime after the sample is annealed at temperature $T$ as shown in Figure 1(a). In first-order approximation, the same prefactor $C$ is also used for $\mathrm{FeB}$ and $\mathrm{FeB}-\mathrm{P}$ complexes in compensated silicon since the electronic properties of both defects are not significantly different $[19,20]$. The total concentration of Fe, $N$ (tot), is determined by measuring the lifetime before and after thermal treatment at $200^{\circ} \mathrm{C}$ for $10 \mathrm{~min}$ [7]. This method can only be used when $N_{\mathrm{B}}$ is smaller than $10^{16} \mathrm{~cm}^{-3}$ [17]. $N\left(\mathrm{Fe}_{\mathrm{i}}\right)$ after thermal treatment at $200^{\circ} \mathrm{C}$ for $10 \mathrm{~min}$ is $(6.1 \pm 0.1) \times 10^{12} \mathrm{~cm}^{-3}$ and $(6.2 \pm$ $0.1) \times 10^{12} \mathrm{~cm}^{-3}$ for compensated and uncompensated silicon, respectively, as shown in Figure $1(\mathrm{~b})$, illustrating that the iron solubility is the same in both materials. The samples are quenched by cooling in water immediately after thermal treatment to reduce the diffusion of iron and thus the complex formation with dopant atoms or iron precipitation. $N\left(\mathrm{Fe}_{\mathrm{i}}\right)$ increases with temperature even above $200^{\circ} \mathrm{C}$ for both samples. This illustrates that not all iron-dopant complexes or small iron silicide clusters dissociated, even at $270^{\circ} \mathrm{C} . \mathrm{N}$ (tot), can however still be determined by the lifetime measurement before and after illumination. The estimated values of $N$ (tot) are $(1.9 \pm 0.2) \times 10^{13} \mathrm{~cm}^{-3}$ and $(1.4 \pm 0.1) \times 10^{13} \mathrm{~cm}^{-3}$ for compensated and uncompensated silicon, respectively. Both values are somewhat higher than the estimated solubility which is due to the prefactor $C$ that varies with B (and/or P) concentration [20] while it is assumed constant for the WT2000. In the following, we focus on the ratio of $N\left(\mathrm{Fe}_{\mathrm{i}}{ }^{+}\right)$ over $N$ (tot) to eliminate the effect of the prefactor $C$.

Figure 2 shows the ratio of $N\left(\mathrm{Fe}_{\mathrm{i}}^{+}\right)$to $N($ tot $)$ at temperatures between 50 and $200^{\circ} \mathrm{C}$ for the compensated and uncompensated samples. Note that $\mathrm{Fe}_{\mathrm{i}}$ concentration is equal 


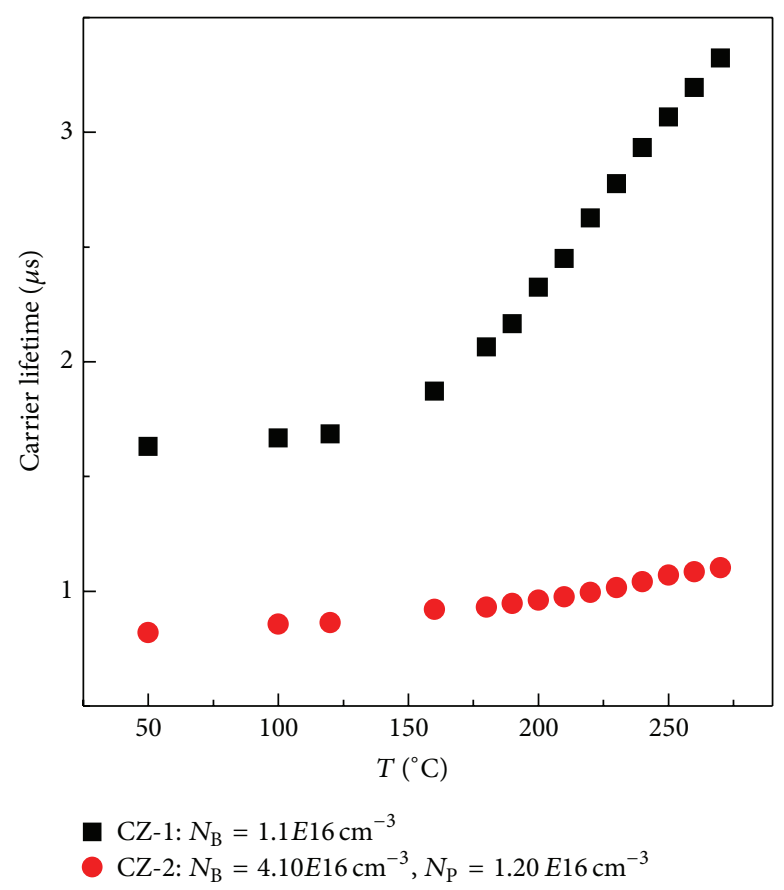

(a)

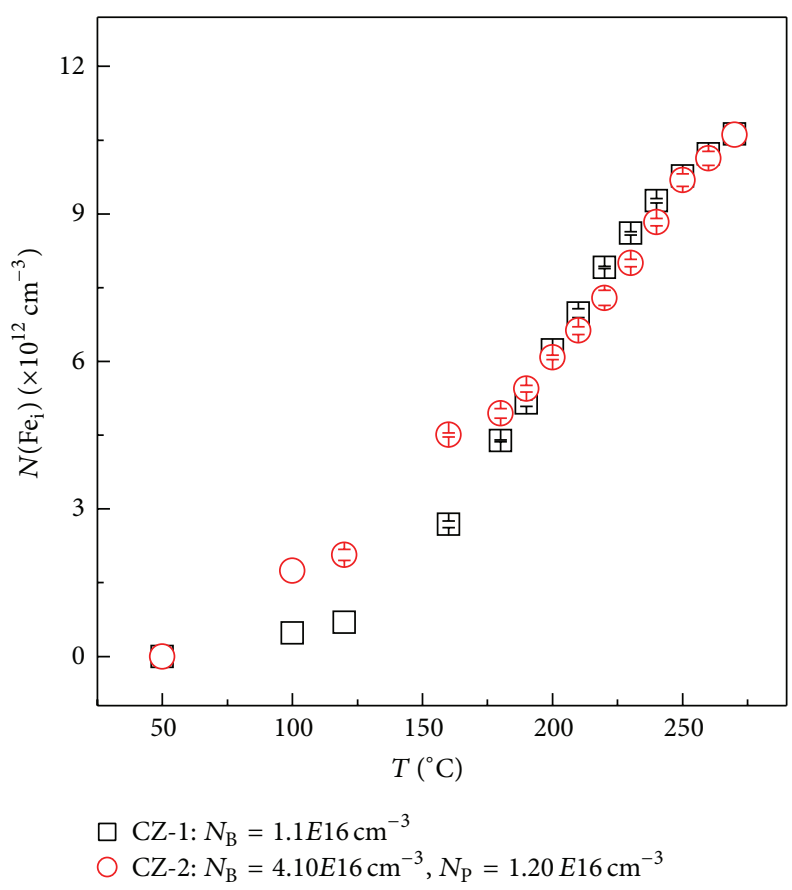

(b)

FIgURE 1: (a) The carrier lifetime as a function of temperature for CZ-1 and CZ-2. (b) The concentration of $\mathrm{Fe}_{\mathrm{i}}$ as a function of temperature for CZ-1 and CZ-2. Black squares and red circles refer to the CZ-1 and CZ-2 samples, respectively.

to $N\left(\mathrm{Fe}_{\mathrm{i}}{ }^{+}\right)$as the Fermi level is below the defect level $E_{v}+$ $0.39 \mathrm{eV}$ of $\mathrm{Fe}^{0 /+}$, for all temperatures studied [7]. It can be seen from Figure 2 that the value of $N\left(\mathrm{Fe}_{\mathrm{i}}{ }^{+}\right) / N($ tot $)$ increases with increasing temperature for both samples. But the increase rate of $N\left(\mathrm{Fe}_{\mathrm{i}}{ }^{+}\right) / N$ (tot) for the uncompensated material is larger than that for the compensated one if temperature is above $100^{\circ} \mathrm{C}$.

In uncompensated material and assuming there are only two carrier recombination centers, that is, $\mathrm{Fe}_{\mathrm{i}}{ }^{+}$and $\mathrm{FeB}$, the equilibrium concentration of $\mathrm{Fe}_{\mathrm{i}}^{+}$at a given temperature is given by [21]:

$$
\frac{N\left(\mathrm{Fe}_{\mathrm{i}}^{+}\right)}{N(\text { tot })}=\frac{1}{\left[1+\left(Z / N_{\mathrm{Si}}\right) N_{\mathrm{B}} \exp \left(E_{b} / \kappa_{\mathrm{B}} T\right)\right]},
$$

where $Z$ is the number of possible orientations of the pair with the same symmetry around one B atom (four for the tetrahedral interstitial site), $N_{\mathrm{Si}}$ is the lattice site density in silicon $\left(5 \times 10^{22} \mathrm{~cm}^{-3}\right), \kappa_{\mathrm{B}}$ is the Boltzmann constant, and $T$ is the absolute temperature. Note that (3) is only valid when iron precipitation can be neglected. In such case the equilibrium FeB concentration, $N(\mathrm{FeB})$, is equal to $\left(N(\mathrm{tot})-N\left(\mathrm{Fe}_{\mathrm{i}}{ }^{+}\right)\right)[11]$. Since, at temperatures above $200^{\circ} \mathrm{C}$, the $\mathrm{B}$ atoms can no longer provide stable traps for iron, it diffuses towards more stable sinks where it agglomerates [7]. Fitting the experimental data by (3), as shown in Figure 2, one obtains $E_{b}=(0.53 \pm 0.02) \mathrm{eV}$ for uncompensated silicon, which is well in the range of 0.45 to $0.65 \mathrm{eV}$ as previously published $[7,10]$ and is close to the electrostatic binding energy of $0.52 \mathrm{eV}$ based on the model of ionic type binding of $\mathrm{FeB}$ pair [7]. The preexponential factor is $(3 \pm 1) \times 10^{-6}$ which is close to the theoretical value of $0.9 \times 10^{-6}$ for $\left(Z N_{\mathrm{B}} / N_{\mathrm{Si}}\right)$ since $N_{\mathrm{B}}$ is $1.1 \times 10^{16} \mathrm{~cm}^{-3}$. As shown in Figure 2, when using the same equation (3) (meaning that one assumes again that there are two carrier recombination centers, i.e., $\mathrm{Fe}_{\mathrm{i}}{ }^{+}$and an iron-dopant complex) for compensated silicon, the best fit yields an effective binding energy of $(0.25 \pm 0.03) \mathrm{eV}$, which is $0.28 \mathrm{eV}$ lower than $E_{b}$ of $\mathrm{FeB}$ in uncompensated silicon. And the preexponential factor is $(4 \pm 3) \times 10^{-3}$ which is three orders of magnitude larger than the value of $\left(Z N_{\mathrm{B}} / N_{\mathrm{Si}}\right), 3.3 \times 10^{-6}$, since $N_{\mathrm{B}}$ is $4.10 \times$ $10^{16} \mathrm{~cm}^{-3}$. It illustrates that $\mathrm{P}$ codoping with $\mathrm{B}$ leads to the creation of different carrier recombination centers, probably besides FeB also FeB-P related complexes. Iron might indeed also form complexes with B-P pairs with a different binding energy than that with $\mathrm{B}$, leading to the observed lower effective binding energy which would be a combination of the binding of FeB and of FeB-P. Substitutional $\mathrm{P}^{+}$close to $\mathrm{B}^{-}$will indeed impact the electrostatic interaction between $\mathrm{Fe}_{\mathrm{i}}{ }^{+}$and $\mathrm{B}_{\mathrm{s}}{ }^{-}$. On the basis of photoluminescence (PL) measurements, Tajima et al. [22] suggested that P and B impurities in solar grade silicon are separated from each other by about 1.9 to $3.3 \mathrm{~nm}$, which is smaller than the capture radius of $\mathrm{B}_{\mathrm{s}}{ }^{-}$for $\mathrm{Fe}_{\mathrm{i}}{ }^{+}$, which is about 5-6 nm $[7,12]$. Therefore $\mathrm{P}_{\mathrm{s}}{ }^{+}$will lead to a lower binding energy of $\mathrm{Fe}_{\mathrm{i}}^{+}$in $\left(\mathrm{Fe}_{\mathrm{i}}{ }^{+} \mathrm{B}_{\mathrm{s}}{ }^{-}-\mathrm{P}_{\mathrm{s}}{ }^{+}\right)$.

The ratio of $N\left(\mathrm{Fe}_{\mathrm{i}}{ }^{+}\right)$to $N($ tot $)$ above $200^{\circ} \mathrm{C}$ for $10 \mathrm{~min}$ has also been measured, as shown in Figure 3. The experimental points are always below the simulated data based on (3) and the difference increases with increasing temperature. This behavior illustrates that some of the dissociated Fe atoms have reassociated with the dopant or have agglomerated into iron precipitates in the bulk or at the wafer surface. Zeng et al. [14] 


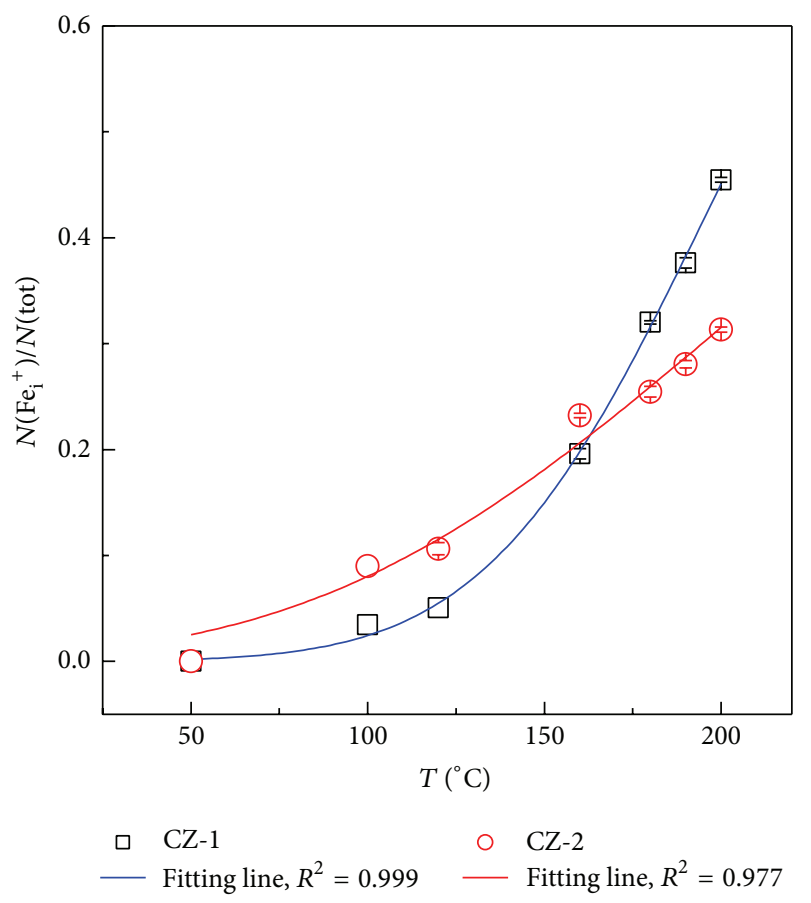

Figure 2: The ratio of $N\left(\mathrm{Fe}_{i}^{+}\right) / N($ tot $)$ as a function of temperature for CZ-1 and CZ-2. Black squares and red circles refer to the CZ-1 and CZ-2 samples, respectively. The solid lines represent the best fits based on (3).

found that the $\mathrm{Fe}$ precipitation at $300-700^{\circ} \mathrm{C}$ is a diffusionlimited process, just like for the association of FeB. Krain et al. [16] obtained an activation energy close to $\mathrm{Fe}_{i}{ }^{+}$migration energy of $0.67 \mathrm{eV}$ [7]. Therefore, we fit the line with (4), taking into account the dissociation of $\mathrm{FeB}$ and the decrease of the iron concentration due to a diffusion-limited reaction:

$$
\begin{aligned}
\frac{N\left(\mathrm{Fe}_{\mathrm{i}}\right)}{N(\text { tot })}= & {\left[1+\frac{Z}{N_{\mathrm{Si}}} N_{\mathrm{B}} \exp \left(\frac{E_{b}}{\kappa_{\mathrm{B}} T}\right)\right]^{-1} } \\
& -A \exp \left(-\frac{E_{m}}{\kappa_{\mathrm{B}} T}\right)
\end{aligned}
$$

where $A$ is a preexponential factor to be fitted and $E_{m}$ is the iron diffusion energy which is fixed at $0.67 \mathrm{eV}$. A best fit is obtained for $A=(6.8 \pm 0.5) \times 10^{4}$ and $E_{b}$ is fixed at value of $(0.53 \pm 0.01) \mathrm{eV}$ with $R^{2}=0.9997$. This result confirms that some of iron has precipitated or reassociated whereby both processes are controlled by iron diffusion.

However, the situation is different in compensated silicon, as shown in Figure 4. In that case, the experimental result for $N\left(\mathrm{Fe}_{\mathrm{i}}^{+}\right) / N($ tot $)$ is greater than the simulated values based on (3), which is in contrast to uncompensated silicon as shown in Figure 3. This is probably due to the formation of FeB-P complexes. Macdonald et al. [8] reported that the diffusion barrier of $\mathrm{Fe}_{\mathrm{i}}{ }^{+}$is not affected by the presence of compensating dopants. As mentioned, $\mathrm{P}_{\mathrm{s}}^{+}$will however affect the electronic interaction between $\mathrm{B}_{\mathrm{s}}{ }^{-}$and $\mathrm{Fe}_{\mathrm{i}}{ }^{+}$. Based on (1a) and (lb),

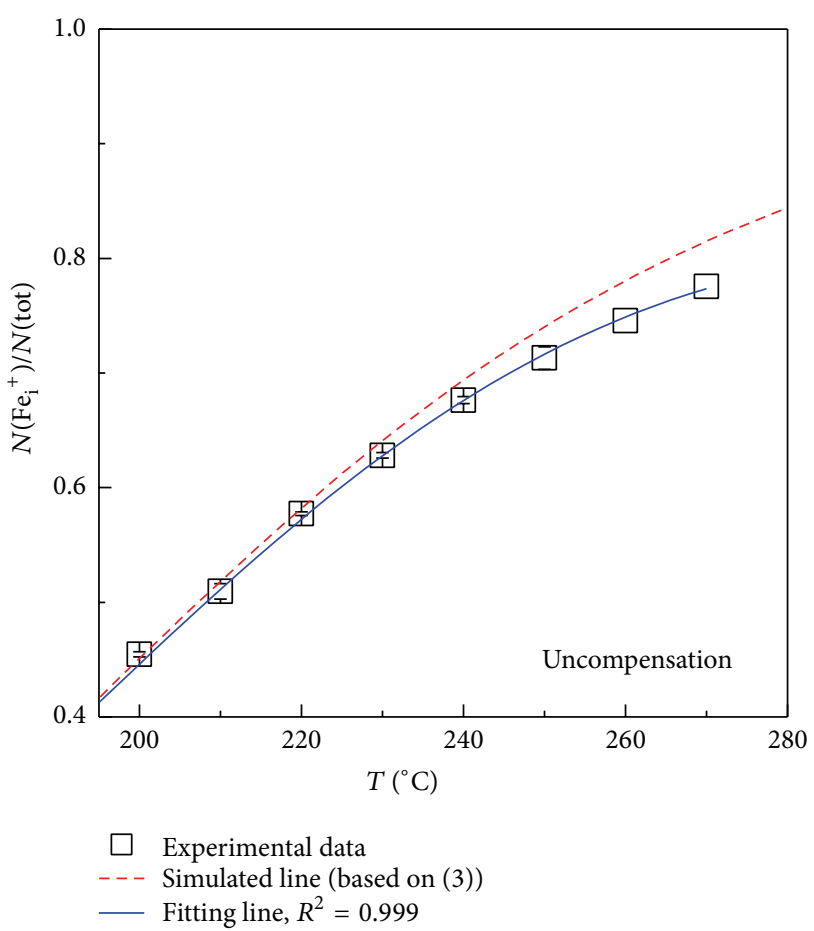

FIgURE 3: The ratio of $N\left(\mathrm{Fe}_{\mathrm{i}}^{+}\right) / N($ tot $)$ as a function of temperature for CZ-1. Black squares refer to the experimental data, the blue solid line represents a best fit, and the red dash line is a simulated line based on the function of $N\left(\mathrm{Fe}_{\mathrm{i}}{ }^{+}\right) / N($ tot $)=1 /(1+2.7 \times$ $\left.10^{-6} \exp \left(0.53 \mathrm{eV} / \kappa_{\mathrm{B}} T\right)\right)$.

the equilibrium reaction taking into account FeB and FeB-P complexes can be written as

$$
\begin{aligned}
\frac{N\left(\mathrm{Fe}_{\mathrm{i}}\right)}{N(\text { tot })}= & a\left[1+\frac{Z}{N_{\mathrm{Si}}}\left(N_{\mathrm{B}}-N_{\mathrm{P}}\right) \exp \left(\frac{E_{b}}{\kappa_{\mathrm{B}} T}\right)\right]^{-1} \\
& +(1-a)\left[1+\frac{Z}{N_{\mathrm{Si}}} N_{\mathrm{P}} \exp \left(\frac{E_{2}}{\kappa_{\mathrm{B}} T}\right)\right]^{-1},
\end{aligned}
$$

where $a$ is the fraction of iron that forms pairs with boron, $E_{2}$ is the binding energy between Fe and the BP pair in the FeB-P complex, and $E_{b}$ is fixed at value of $0.53 \mathrm{eV}$. The best fit yields $E_{2}=(0.45 \pm 0.17) \mathrm{eV}$ and $a=(0.74 \pm 0.05)$ with $R^{2}=0.995$, as shown in Figure 4 . The value of $a$ suggests that $26 \%$ of the iron has formed FeB-P complexes which is in good agreement with the ratio of $N_{\mathrm{P}}$ over $N_{\mathrm{B}}\left(1.1 \times 10^{16} \mathrm{~cm}^{-3} / 4.10 \times 10^{16} \mathrm{~cm}^{-3}\right)$. This illustrates once more that, besides the recombination centers related to $\mathrm{FeB}$ and $\mathrm{Fe}_{\mathrm{i}}{ }^{+}$, also the FeB-P complex is an effective recombination center in compensated silicon. The reduced binding energy of $\mathrm{FeB}$ in the FeB-P complexes results in $0.28 \mathrm{eV}$ decrease of the apparent binding energy in compensated silicon.

For further support of the above mentioned model, the binding energy of FeB and FeB-P complexes has been calculated using the density-functional theory (DFT). All calculations were performed with the Vienna ab initio simulation package (VASP) [23]. A 216-atom supercell, Brillouinzone sampling with $2 \times 2 \times 2$ Monkhorst-Pack $k$-point 


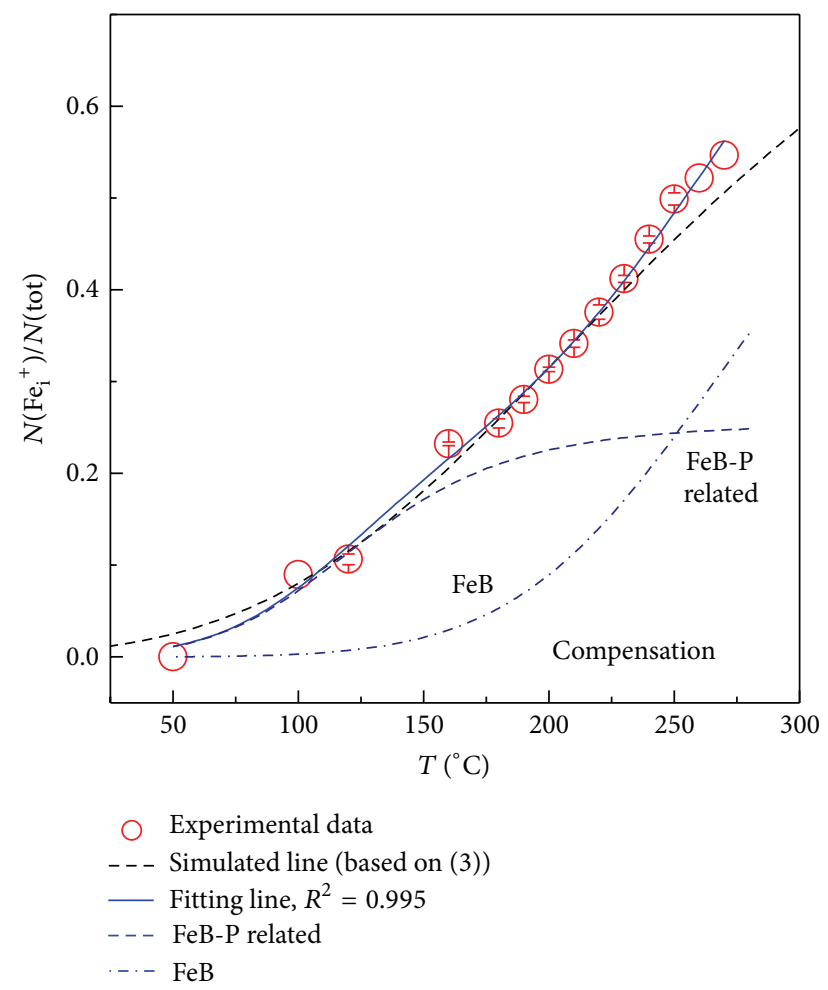

FIGURE 4: The ratio of $N\left(\mathrm{Fe}_{\mathrm{i}}^{+}\right) / N($ tot $)$ as a function of temperature for CZ-2. Red circles refer to the experimental data, and the black dash line is a simulated line based on the function of $N\left(\mathrm{Fe}_{\mathrm{i}}^{+}\right) / N($ tot $)=1 /\left(1+4 \times 10^{-3} \exp \left(0.25 \mathrm{eV} / \kappa_{\mathrm{B}} T\right)\right)$. The blue solid line represents a best fit which can be separated by the dark blue short dash dot line based on the function of $0.74 /(1+2.6 \times$ $\left.10^{-5} \exp \left(0.53 \mathrm{eV} / \kappa_{\mathrm{B}} T\right)\right)$ for $\mathrm{FeB}$ and the dark blue short dash line based on the function of $0.16 /\left(1+2 \times 10^{-6} \exp \left(0.45 \mathrm{eV} / \kappa_{\mathrm{B}} T\right)\right)$ for FeB-P.

sampling [24], and the plane wave basis set with kinetic energy cutoff of $480 \mathrm{eV}$ were used. The generalized gradient approximation (GGA) is applied with the projector augmented wave (PAW) $[25,26]$ method and the PerdewBurke-Ernzerhof exchange-correlation functional [27]. The structures were optimized until the forces on each atom were smaller than $0.01 \mathrm{eV} / \AA$. The convergence criterion for energy was chosen as $10^{-5} \mathrm{eV}$. Finally, the GGA $+U$ method $[28,29]$ was used to account for on-site correlation at $\mathrm{Fe}$ sites. The effective Coulomb exchange interaction $U_{\text {eff }}(=U-J)$ is about $3.6(=4-0.4) \mathrm{eV}$ for the Fe atom [30]. $E_{b}$ of $\left(\mathrm{Fe}_{\mathrm{i}}{ }^{+} \mathrm{B}_{\mathrm{s}}{ }^{-}\right)$ pairs is $0.71 \mathrm{eV}$, while it is $0.61 \mathrm{eV}$ for $\mathrm{Fe}$ and $\mathrm{B}$ in $\left(\mathrm{Fe}_{i}{ }^{+} \mathrm{B}_{\mathrm{s}}{ }^{-} \mathrm{P}_{\mathrm{s}}^{+}\right)$ complexes. The difference of $0.10 \mathrm{eV}$ agrees well with $0.08 \mathrm{eV}$ deduced from the experimental results. This illustrates again that $\mathrm{P}$ located close to $\mathrm{B}$ weakens the $E_{b}$ of $\left(\mathrm{Fe}_{\mathrm{i}}{ }^{+} \mathrm{B}_{\mathrm{s}}{ }^{-}\right)$pairs. Furthermore, the $\mathrm{Fe}_{\mathrm{i}}$ atom does not pair with $\mathrm{P}_{\mathrm{s}}$ since $E_{b}$ is smaller than zero.

In summary, $\mathrm{Fe}_{\mathrm{i}}$ behavior and properties in B-P codoped silicon have been studied. The apparent binding energy of iron-dopant complexes in compensated silicon of $(0.25 \pm 0.03) \mathrm{eV}$ is $0.28 \mathrm{eV}$ lower than that of $\mathrm{FeB}$ in uncompensated silicon. The binding energy for Fe with the $\mathrm{B}-\mathrm{P}$ pair is $(0.45 \pm 17) \mathrm{eV}$ compared with $0.53 \mathrm{eV}$ for $\mathrm{FeB}$ in uncompensated silicon. Calculation results show that $\mathrm{P}$ atom reduces $E_{b}$ of FeB of $0.10 \mathrm{eV}$. The results are of significance for understanding the behavior of $\mathrm{FeB}$ in compensated silicon.

\section{Conflict of Interests}

The authors declare that there is no conflict of interests regarding the publication of this paper.

\section{Acknowledgments}

This project is supported by the National Natural Science Foundation of China (nos. 51532007, 61574124, and 61274057), and the authors are also grateful to Professor Duanlin Que for his supervision.

\section{References}

[1] D. Sarti and R. Einhaus, "Silicon feedstock for the multicrystalline photovoltaic industry," Solar Energy Materials and Solar Cells, vol. 72, no. 1-4, pp. 27-40, 2002.

[2] S. Pizzini, "Towards solar grade silicon: challenges and benefits for low cost photovoltaics," Solar Energy Materials and Solar Cells, vol. 94, no. 9, pp. 1528-1533, 2010.

[3] D. MacDonald, A. Liu, A. Cuevas, B. Lim, and J. Schmidt, "The impact of dopant compensation on the boron-oxygen defect in $p$ - and $n$-type crystalline silicon," Physica Status Solidi A: Applications and Materials Science, vol. 208, no. 3, pp. 559-563, 2011.

[4] S. Pizzini and C. Calligarich, "On the effect of impurities on the photovoltaic behavior of solar-grade silicon I: the role of boron and phosphorous primary impurities in $\mathrm{p}$-type single-crystal silicon," Journal of the Electrochemical Society, vol. 131, no. 9, pp. 2128-2132, 1984.

[5] D. Macdonald and A. Cuevas, "Recombination in compensated crystalline silicon for solar cells," Journal of Applied Physics, vol. 109, no. 4, Article ID 043704, 2011.

[6] S. Zhao, L. V. C. Assali, J. F. Justo, G. H. Gilmer, and L. C. Kimerling, "Iron-acceptor pairs in silicon: structure and formation processes," Journal of Applied Physics, vol. 90, no. 6, Article ID 2744, 2001.

[7] A. A. Istratov, H. Hieslmair, and E. R. Weber, "Iron and its complexes in silicon," Applied Physics A: Materials Science and Processing, vol. 69, no. 1, pp. 13-44, 1999.

[8] D. Macdonald, A. Cuevas, and L. J. Geerligs, "Measuring dopant concentrations in compensated $p$-type crystalline silicon via iron-acceptor pairing," Applied Physics Letters, vol. 92, no. 20, Article ID 202119, 2008.

[9] L. C. Kimerling and J. L. Benton, "Electronically controlled reactions of interstitial iron in silicon," Physica $B+C$, vol. 116, no. 1-3, pp. 297-300, 1983.

[10] E. R. Weber, "Transition metals in silicon," Applied Physics A: Materials Science \& Processing, vol. 30, no. 1, pp. 1-22, 1983.

[11] K. Lauer, A. Laades, H. Ubensee, H. Metzner, and A. Lawerenz, "Detailed analysis of the microwave-detected photoconductance decay in crystalline silicon," Journal of Applied Physics, vol. 104, Article ID 104503, 2008.

[12] X. Zhu, X. Yu, X. Li, P. Wang, and D. Yang, "Quantification of characteristic parameters for the dissociation kinetics of ironboron pairs in Czochralski silicon," Scripta Materialia, vol. 64, no. 3, pp. 217-220, 2010. 
[13] X. Zhu, X. Yu, X. Chen, J. Jiang, and D. Yang.

[14] Y. Zeng, D. Yang, Z. Xi, W. Wang, and D. Que, "Iron precipitation in as-received Czochralski silicon during low temperature annealing," Materials Science in Semiconductor Processing, vol. 12, no. 4-5, pp. 185-188, 2009.

[15] F. S. Ham, "Diffusion-limited growth of precipitate particles," Journal of Applied Physics, vol. 30, no. 10, article 1518, 1959.

[16] R. Krain, S. Herlufsen, and J. Schmidt, "Internal gettering of iron in multicrystalline silicon at low temperature," Applied Physics Letters, vol. 93, no. 15, Article ID 152108, 2008.

[17] G. Zoth and W. Bergholz, "A fast, preparation-free method to detect iron in silicon," Journal of Applied Physics, vol. 67, no. 11, article 6764, 1990.

[18] D. H. Macdonald, L. J. Geerligs, and A. Azzizi, "Iron detection in crystalline silicon by carrier lifetime measurements for arbitrary injection and doping," Journal of Applied Physics, vol. 95, no. 3, pp. 1021-1028, 2004.

[19] D. Macdonald and A. Liu, "Recombination activity of ironboron pairs in compensated p-type silicon," Physica Status Solidi (B), vol. 247, no. 9, pp. 2218-2221, 2010.

[20] J. Schmidt and D. Macdonald, "Recombination activity of irongallium and iron-indium pairs in silicon," Journal of Applied Physics, vol. 97, no. 11, Article ID 113712, 2005.

[21] D. Macdonald, T. Roth, P. N. K. Deenapanray, K. Bothe, P. Pohl, and J. Schmidt, "Formation rates of iron-acceptor pairs in crystalline silicon," Journal of Applied Physics, vol. 98, no. 8, Article ID 083509, 2005.

[22] M. Tajima, T. Iwai, H. Toyota, S. Binetti, and D. MacDonald, "Donor-acceptor pair luminescence in compensated Si for solar cells," Journal of Applied Physics, vol. 110, no. 4, Article ID 043506, 2011.

[23] G. Kresse and J. Furthmüller, "Efficient iterative schemes for ab initio total-energy calculations using a plane-wave basis set," Physical Review B, vol. 54, no. 16, pp. 11169-11186, 1996.

[24] H. J. Monkhorst and J. D. Pack, "Special points for Brillouinzone integrations," Physical Review B, vol. 13, no. 12, Article ID 5188, 1976.

[25] P. E. Blöchl, "Projector augmented-wave method," Physical Review B, vol. 50, no. 24, Article ID 17953, 1994.

[26] G. Kresse and D. Joubert, "From ultrasoft pseudopotentials to the projector augmented-wave method," Physical Review B, vol. 59, no. 3, pp. 1758-1775, 1999.

[27] J. P. Perdew, K. Burke, and M. Ernzerhof, "Generalized gradient approximation made simple," Physical Review Letters, vol. 77, no. 18, pp. 3865-3868, 1996.

[28] V. I. Anisimov, J. Zaanen, and O. K. Andersen, "Band theory and mott insulators: hubbard U instead of stoner I," Physical Review B, vol. 44, no. 3, pp. 943-954, 1991.

[29] V. I. Anisimov, F. Aryasetiawan, and A. I. Lichtenstein, "Firstprinciples calculations of the electronic structure and spectra of strongly correlated systems: the LDA + U method," Journal of Physics Condensed Matter, vol. 9, no. 4, pp. 767-808, 1997.

[30] V. I. Anisimov, R. Hlubina, M. A. Korotin et al., "First-order transition between a small gap semiconductor and a ferromagnetic metal in the isoelectronic alloy $\mathrm{FeSi}_{1-x} \mathrm{Ge}_{x}$," Physical Review Letters, vol. 89, no. 25, Article ID 257203, 4 pages, 2002. 

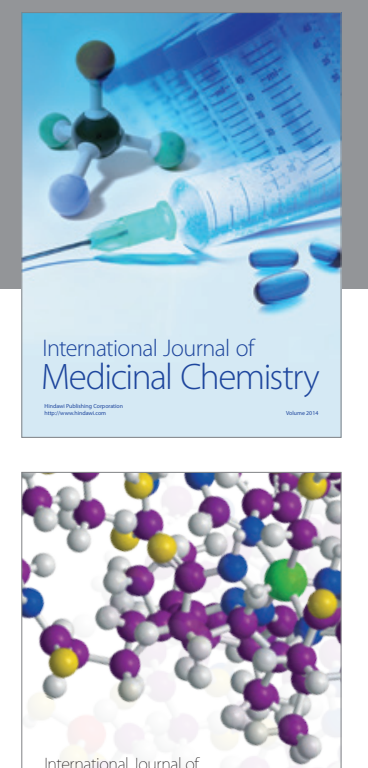

\section{Carbohydrate} Chemistry

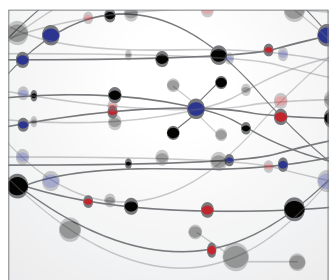

The Scientific World Journal
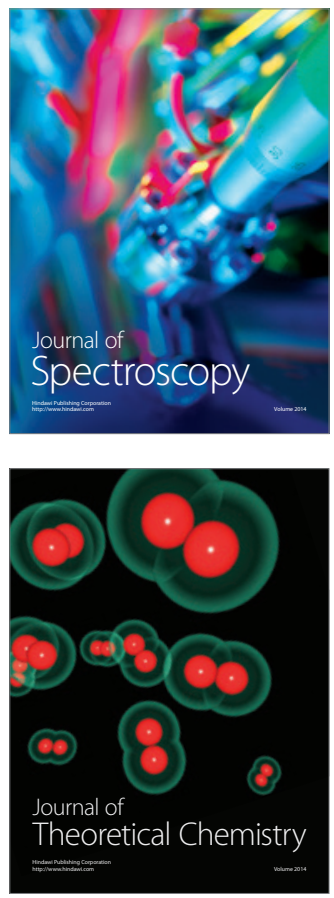
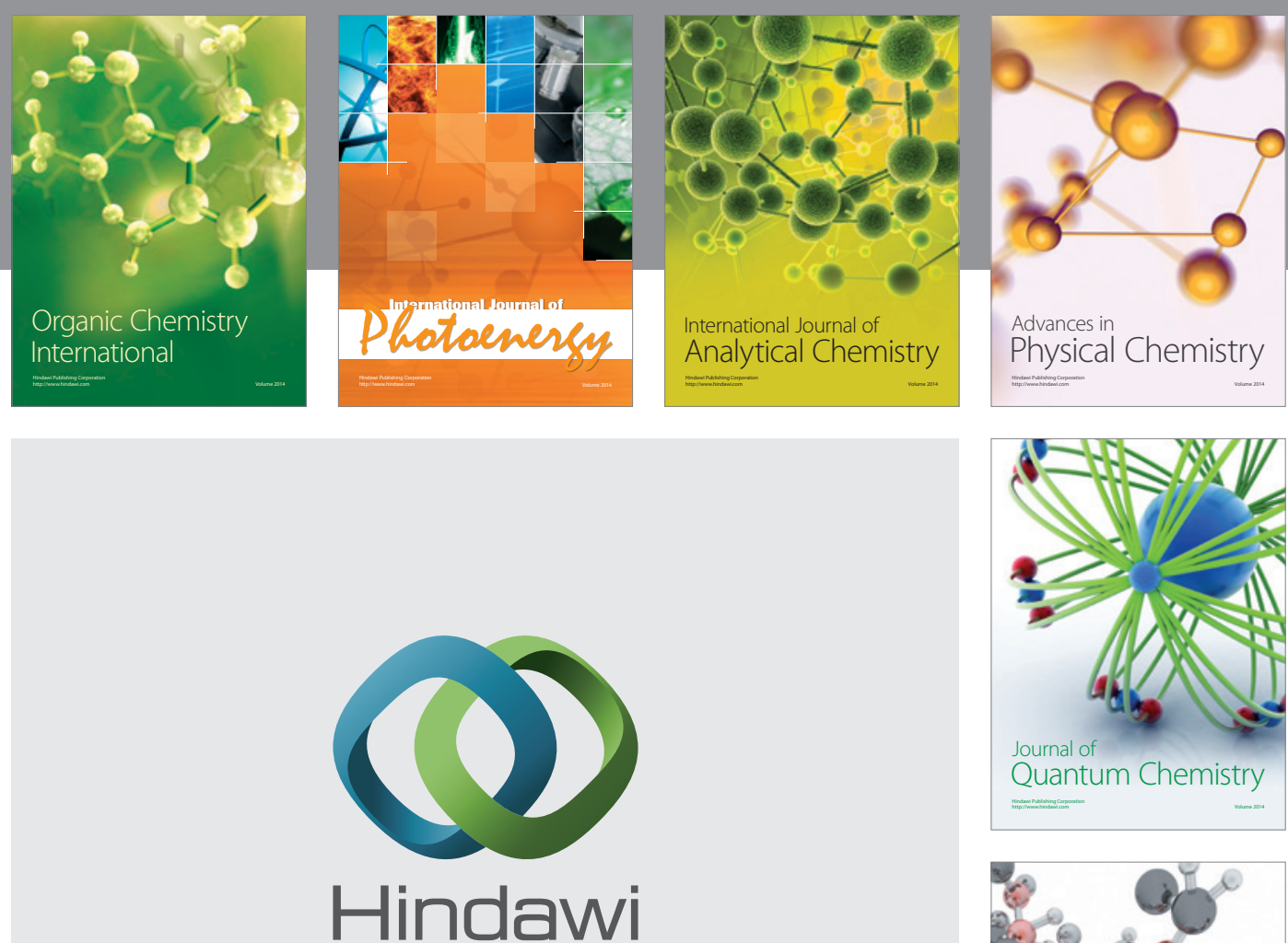

Submit your manuscripts at

http://www.hindawi.com

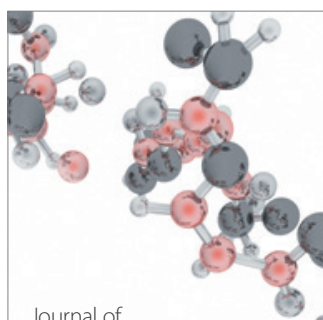

Analytical Methods

in Chemistry

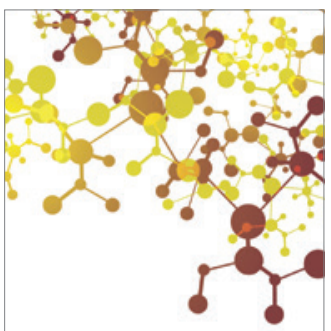

Journal of

Applied Chemistry

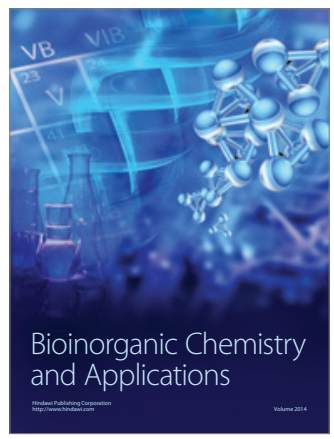

Inorganic Chemistry
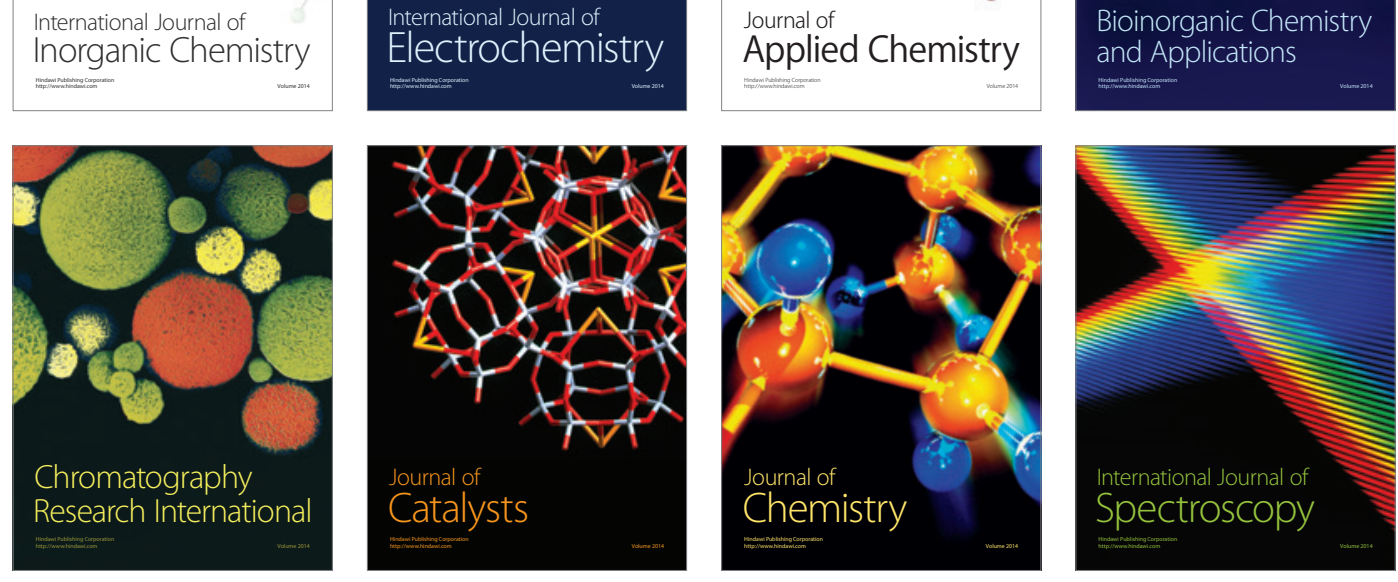